\title{
Human Cord Blood-Derived Mast Cells Are Activated by the Nod1 Agonist M-TriDAP to Release Pro-Inflammatory Cytokines and Chemokines
}

\author{
Mattias Enoksson Karin F.K. Ejendal Sarah McAlpine Gunnar Nilsson \\ Carolina Lunderius-Andersson \\ Department of Medicine, Clinical Immunology and Allergy Unit, Karolinska Institutet, Stockholm, Sweden
}

\section{Key Words}

Human mast cells $\cdot$ Innate immunity $\cdot$ Nod1 $\cdot$ Toll-like receptor

\begin{abstract}
Mast cells are among the first cells of our immune system to encounter exogenous danger. Intracellular receptors such as nucleotide-binding oligomerization domain (Nod) play an important role in responding to invading pathogens. Here, we have investigated the response of human mast cells to the Nod1 ligand M-TriDAP. Human cord blood-derived mast cells (CBMCs) were activated with M-TriDAP alone, or in combination with the Toll-like receptor (TLR) ligands lipopolysaccharide (LPS) and zymosan. Release of pro-inflammatory chemokines and cytokines was measured by ELISA, cytometric bead array and LUMINEX, and degranulation was evaluated by analysis of histamine release. M-TriDAP induced a dose-dependent release of IL- 8, MIP- $1 \alpha$, MIP- $1 \beta$ and TNF. In contrast, degranulation could not be observed. When cells were treated with M-TriDAP in combination with the TLR4 agonist LPS, but not with TLR2 agonist zymosan, the secretion of cytokines was augmented. We here present results demonstrating that human CBMCs are stimulated by the
\end{abstract}

Nod1 agonist M-TriDAP alone and in combination with LPS to produce pro-inflammatory cytokines and chemokines. Our results add to the concept that mast cells constitute an important part of our host defense, as they are equipped with several types of important pattern recognition receptors, including TLRs and Nod.

Copyright $\odot 2010$ S. Karger AG, Basel

\section{Introduction}

Mast cells are mainly located at the interface between the host and the external environment, where they are among the first cells to encounter exogenous danger signals such as antigens and pathogens $[1,2]$. The localization of these cells, combined with their ability to rapidly release stored granule mediators upon activation and to secrete de novo synthesized mediators, makes them potent orchestrators of inflammatory responses [3, 4]. Therefore, it is not surprising that mast cells are involved in many inflammatory diseases, such as asthma, allergy, inflammatory bowel disease and rheumatoid arthritis [5]. Mast cells have also important protective functions, including being part of our host defence. One of the first

\section{KARGER \\ Fax +4161306 1234 \\ E-Mail karger@karger.ch}

www.karger.com
(C) 2010 S. Karger AG, Basel

$1662-811 X / 11 / 0032-0142 \$ 38.00 / 0$

Accessible online at:

www.karger.com/jin
Dr. Carolina Lunderius Andersson

Department of Medicine, Clinical Immunology and Allergy Unit Karolinska Institutet, KS L2:04

SE-171 76 Stockholm (Sweden)

Tel. +46 8517766 97, Fax +4683357 24, E-Mail carolina.lunderius@ki.se 
and best illustrations of the role of mast cells in the defence against bacterial infections was demonstrated using mast cell-deficient mice $[6,7]$. These mice are not protected against pathogens unless they are reconstituted with mast cells.

A combination of different mechanisms are used by mast cells to sense and respond to pathogens [8], either directly through receptors such as Toll-like receptors (TLRs) [9], dectin-1 [10] and the mannose receptor CD48 [11] or indirectly, for instance through cross-linking of Fc receptors by superantigens [12]. These events initiate signalling pathways that lead to activation of nuclear factor $\kappa \mathrm{B}(\mathrm{NF \kappa} \mathrm{B})$, which in turn activate pro-inflammatory genes, including genes for cytokines and chemokines.

In recent years, a number of pattern-recognition receptors (PRRs) of the host cells have been described as binding different pathogen-associated molecular patterns (PAMPs) $[13,14]$. TLRs represent prominent examples of PRRs. A selection of PAMPs includes bacterial components such as lipopolysaccharide (LPS), nucleic acids, zymosan and peptidoglycan (PGN); thus, PAMPs are composed of a great variety of structures [15]. The effectiveness of the innate sensing network relies on the numerous receptors, their unique specificities, and how they cooperate in the recognition of different structures of pathogens.

In addition to cell surface receptors, intracellular PRRs such as the nucleotide-binding oligomerization domain proteins Nod1 and Nod2, are also important players in responding to pathogens [16]. Nod proteins sense inflammatory stimuli through their leucine-rich repeat domains [17]. As Nod proteins are intracellular, they are primarily thought to sense intracellular bacteria. However, recent studies have shown that the Nod ligands may also be translocated into the cytoplasm by various mechanisms $[18,19]$. Whereas Nod1 recognizes peptidoglycans from mainly Gram-negative bacteria, such as Helicobacter pylori, Nod2 can sense both Gram-negative and -positive bacteria through motifs such as muramyl dipeptide (MDP) found in all bacterial peptidoglycans [20]. GM-TriDAP (GlcNAc-MurNAc-L-Ala- $\gamma$-D-Glumeso-DAP) is a naturally occurring peptidoglycan degradation product specifically recognized by Nod1 [20].

The aim of the present study was to investigate the response of human mast cells to M-TriDAP, a diaminopimelate-containing MurNAc tripeptide, which is specifically recognized by Nod1 [20-22]. Here, human cord blood-derived mast cells (CBMCs) were activated with M-TriDAP alone or in combination with the TLR ligands LPS and zymosan, and the release of pro-inflammatory mediators was measured. Our results demonstrate that activation of the intracellular Nod1 protein leads to a degranulation-independent secretion of cytokines, thus providing further evidence for the role of mast cells as important contributors to host defence.

\section{Materials and Methods}

\section{Reagents}

The calcium ionophore A23187, LPS from Escherichia coli O55:B5, zymosan A from Saccharomyces cerevisiae and SP600125 were all purchased from Sigma Aldrich, St. Louis, Mo., USA. U1tra-pure M-TriDAP was synthesized as previously described [20], and kindly provided by Drs. Mireille Hervé and Dominique Mengin-Lecreulx, Université Paris-Sud, France. Cell signalling inhibitors SB203580, LY294002, PD98059 and wortmannin were from Calbiochem, Merck KgaA, Darmstadt, Germany.

\section{Mast Cell Cultures}

CBMCs were obtained as previously described [23, 24]. Briefly, CD34+ cells were purified with CD34 MicroBead kit (Miltenyi Biotec, Bergisch Gladbach, Germany) from umbilical cord blood and maintained in complete StemPro medium (Invitrogen, Carlsbad, Calif., USA) supplemented with $100 \mathrm{ng} / \mathrm{ml} \mathrm{SCF}, 10 \mathrm{ng} / \mathrm{ml}$ IL-6 (Amgen, Thousand Oaks, Calif., USA), 2 mM L-glutamine, $100 \mathrm{units} / \mathrm{ml}$ penicillin and $0.1 \mathrm{mg} / \mathrm{ml}$ streptomycin for the first 4 weeks. In addition, during the first week of culture, $10 \mathrm{ng} / \mathrm{ml} \mathrm{IL-3}$ was included in the media. After 4 weeks, the cells were cultured in RPMI 1640 medium (Sigma Aldrich, St. Louis, Mo., USA) supplemented with 10\% FBS (Invitrogen, Carlsbad, Calif., USA), 100 $\mathrm{ng} / \mathrm{ml} \mathrm{SCF}$ and $10 \mathrm{ng} / \mathrm{ml} \mathrm{IL-6,} \mathrm{0.01} \mathrm{M} \mathrm{HEPES,} \mathrm{0.5×} \mathrm{non-essential}$ amino acids, $2 \mathrm{mM} \mathrm{L-glutamine,} 100$ units/ml penicillin, $0.1 \mathrm{mg} /$ $\mathrm{ml}$ streptomycin and $48 \mu \mathrm{M} \beta$-mercaptoethanol (Sigma Aldrich, St. Louis, Mo., USA). Mast cell maturity and purity was evaluated by staining for the mast cell-specific protease tryptase [25]. The purity of mast cells used in experiments exceeded 95\%. The use of CBMCs in this study was approved by the ethical committee at Uppsala University Hospital, Sweden. All donors gave informed consent.

Analysis of Nod1 and Nod2 Protein Expression in CBMCs

Nod1 and Nod2 protein expression in CBMCs was analyzed by flow cytometry using a FACSCalibur (Becton Dickinson, Stockholm, Sweden). Briefly, CBMCs were fixed with Biolegends fixation buffer and Fc receptors were blocked using Human TruStain Fc Receptor Blocking Solution, after which cells were permeabilized using a permeabilization buffer (all from Biolegend, San Diego, Calif., USA). To detect intracellular expression of Nod1, the following antibodies were utilized: $\alpha$-CARD4 (Abcam, Cambridge, UK), followed by a fluorescein (FITC)-labelled secondary antibody (swine- $\alpha$-rabbit IgG; Dako, Glostrup, Denmark). Rabbit IgG was used as isotype control (Dako). To detect Nod 2 expression, an $\alpha$-CARD15 antibody (clone 2D9; Abcam) was used followed by a FITC-labelled secondary antibody (rabbit$\alpha$-mouse IgG; Dako). Mouse IgG1 was used as isotype control (Dako). 
In vitro Stimulation of Human Mast Cells

Mast cells were washed and seeded in 48-well plates at a final concentration of $1 \times 10^{5}$ cells $/ \mathrm{ml}$ and treated with different stimuli: medium alone, $0.5 \mu \mathrm{M}$ A23187, or 15-1,500 nM M-TriDAP, either alone or in combination with $0.1 \mu \mathrm{g} / \mathrm{ml}$ LPS or $0.001 \mu \mathrm{g} / \mathrm{ml}$ zymosan. Cell-free supernatants were collected at $30 \mathrm{~min}$ and $24 \mathrm{~h}$ post-stimulation and kept at $-20^{\circ} \mathrm{C}$ until analysis. For analysis of cell signalling pathways, mast cells were washed and seeded in 48-well plates at a final concentration of $1 \times 10^{5}$ cells $/ \mathrm{ml}$, pretreated with inhibitors $(1 \mu \mathrm{M}$ SP600125 inhibits JNK; $0.1 \mu \mathrm{M}$ Wortmannin inhibits PI3K; $50 \mu \mathrm{M}$ LY294002 inhibits PI3K; 20 $\mu \mathrm{M}$ PD98059 inhibits MAPK; $10 \mu \mathrm{M}$ SB203580 inhibits p38 and RIP2/RICK) for $30 \mathrm{~min}$ and then treated with different stimuli; medium alone, $0.5 \mu \mathrm{M}$ A23187 or $1500 \mathrm{nM}$ M-TriDAP. Cell-free supernatants were collected at $24 \mathrm{~h}$ after treatment and kept at $-20^{\circ} \mathrm{C}$ until analysis of released mediators.

\section{Monitoring Mast Cell Responses}

Histamine levels were analyzed by a specific enzyme immunoassay kit (Immunotech, Beckman Coulter, Marseille, France) and concentrations of leukotrienes were measured using Leukotriene C4/D4/E4 Biotrak EIA System (Amersham Biosciences GE Healthcare, Uppsala, Sweden). To measure IL-8 levels, human IL-8 Cytoset, a commercially available ELISA was used (Biosource International, Invitrogen, Camarillo, Calif., USA). Human $\beta$-defensin 2-release was measured by ELISA (Alpha Diagnostic, San Antonio, Tex., USA). The release of GM-CSF, IL-1 $\beta$, MIP-1 $\alpha$, MIP-1 $\beta$, MCP-1 and TNF was analyzed with Cytometric Bead Array Flex sets (BD Biosciences, San Diego, Calif., USA) or Luminex (Millipore, Billerica, Mass., USA). Histamine and leukotrienes were measured in the supernatants collected $30 \mathrm{~min}$ post stimulation, whereas cytokine, chemokine and HBD2 release was analyzed in supernatants collected $24 \mathrm{~h}$ after stimulation.

\section{Statistical and Data Analysis}

The Student $t$ test or the Mann-Whitney test were employed for statistical analyses, with $\mathrm{p}<0.05$ being considered statistically significant. Due to high variations in secreted IL-8 levels between donors (intradonor variations; fig. 3a), the values were normalized to those of untreated cells for each donor. Thus, IL-8 secretion data in figures 3 and 5 are presented as a stimulation index, which represents values for treated cells divided by values for untreated cells.

\section{Results}

\section{Nod1 Protein is Expressed Intracellularly in Human CBMCs}

Several recent studies have reported the expression of Nod-like receptors (NLRs) in monocytes, dendritic cells, epithelial cells and fibroblasts (reviewed in [21]). To assess the expression of Nod1 and Nod2 in human CBMCs, we analyzed intracellular expression of these receptors in healthy blood donors (fig. 1). While all tested donors expressed Nod1 protein (percent Nod1 ${ }^{+}$CBMCs: $75.4 \pm$ $8.3 \%, \mathrm{n}=4$ ), only 1 donor expressed Nod 2 intracellularly,

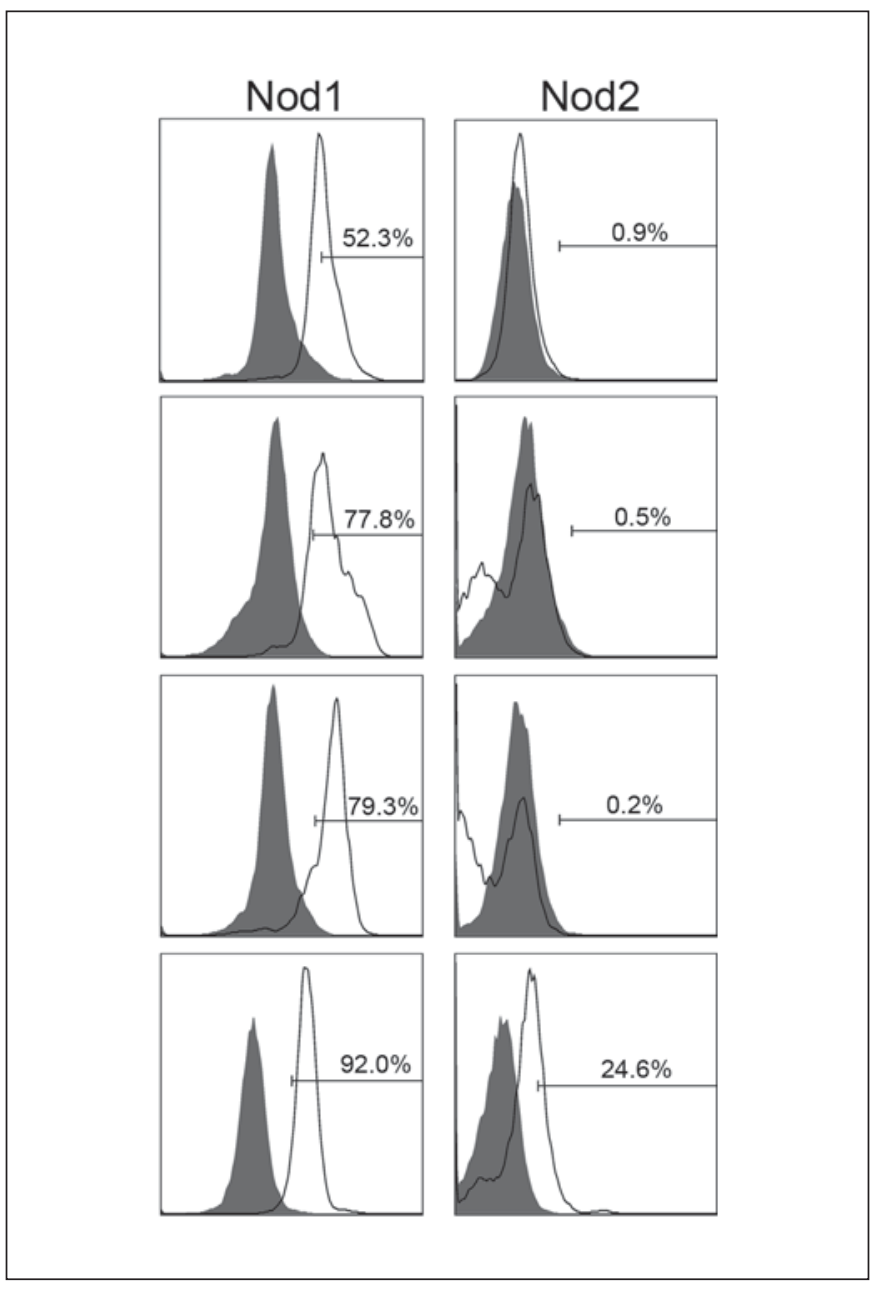

Fig. 1. Nod1 and Nod2 expression in human CBMCs. Intracellular expression of Nod 1 and Nod 2 in CBMCs from 4 healthy blood donors was determined by flow cytometry. Data from 4 representative donors are shown. Filled histograms represent isotype control.

at low levels (percent Nod2 ${ }^{+}$CBMCs: $6.6 \pm 6.0 \%, n=4$ ). It has previously been reported that Nod 2 expression can be upregulated in various ways $[26,27]$. Therefore, we pre-treated CBMCs with either $0.1-0.5 \mu \mathrm{g} / \mathrm{ml}$ LPS, $0.1-$ $0.5 \mu \mathrm{g} / \mathrm{ml}$ IFN- $\gamma$ or $0.1-0.5 \mu \mathrm{M} 1 \alpha, 25$-dihydroxyvitamin D3, but could not detect an upregulated Nod2 expression in these cells (data not shown).

\section{M-TriDAP Does Not Induce Degranulation or}

Secretion of Cysteinyl Leukotrienes in CBMCs

Various stimuli cause mast cells to undergo rapid degranulation and thereby release pre-formed inflammatory mediators stored in granules. Here we investigated 


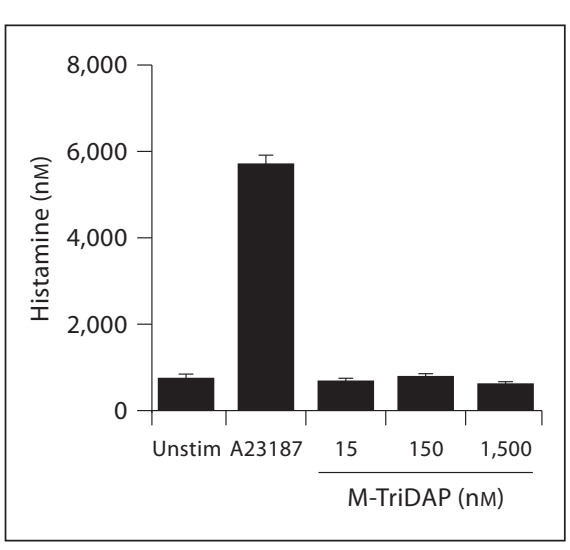

Fig. 2. CBMCs do not release histamine in response to M-TriDAP treatment. Histamine release was analyzed in CBMCs treated for 30 min with M-TriDAP. CBMCs treated with a calcium ionophore (0.5 $\mu \mathrm{M}$ A23187) and medium alone were used as positive and negative controls, respectively. The values presented are means \pm SEM ( $\mathrm{n}=4$ healthy blood donors).

whether treatment of CBMCs with the Nod1 specific agonist M-TriDAP alone or in combination with the TLR ligands LPS or zymosan, induced degranulation, assessed as histamine release. Addition of M-TriDAP alone (fig. 2) or in combination with LPS or zymosan (data not shown) did not induce significant histamine release. As a positive control, cells were activated with A23187, which profoundly stimulated the release of histamine. We next investigated whether M-TriDAP would affect the synthesis of cysteinyl leukotrienes. Similarly to the lack of effect on degranulation, we did not observe secretion of cysteinyl leukotrienes (data not shown), not even in combination with LPS or zymosan. As expected, the calcium ionophore A23187 induced release of cysteinyl leukotrienes (ranging from 317.4 to $565.4 \mathrm{pg} / \mathrm{ml}$, data not shown). Collectively, these data indicate that the Nod1 agonist MTriDAP does not have an effect on degranulation or cysteinyl leukotriene synthesis in human mast cells.

\section{M-TriDAP Induces IL-8 Secretion by CBMCs}

Human IL-8 is a pro-inflammatory chemokine involved in the recruitment of neutrophils, as well as other cells, to the site of inflammation and is therefore an important measure of the inflammatory response. Human CBMCs were activated with M-TriDAP at different concentrations, using medium alone or A23187 as negative and positive controls, respectively $(0.5 \mu \mathrm{M} \mathrm{A} 23187$ induced approximately $12,000 \pm 3,000 \mathrm{pg} / \mathrm{ml} \mathrm{IL-8} \mathrm{in}$ CBMCs; $n=5$ ). As shown in figure $3 \mathrm{a}$ and $\mathrm{b}$, the highest concentration of M-TriDAP used (1,500 nM) induced an increase in IL- 8 secretion by CBMCs. Due to high variations in secreted IL-8 levels between donors (intradonor variations; fig. 3a), results are shown as a stimulation index (see Materials and Methods). Even though we could not detect Nod2 expression in CBMCs, we attempted to activate cells with MDP, a Nod2 agonist. However, CBMCs treated with MDP (ranging from 15 to 1,500 nM) neither induced degranulation nor the release of IL-8 (data not shown).

Signalling through Nod1 is mediated via several intertwined yet separate pathways. To further elucidate the signalling schemes in mast cells, a specific signalling pathway was inhibited at a time during activation of the cells. As a readout system, IL-8 secretion was measured by ELISA. Pre-incubation of CBMCs with the p38 inhibitor SB203580 prior to treatment with $1,500 \mathrm{nM} \mathrm{M}$ TriDAP significantly reduced IL- 8 secretion in these cells (fig. 3c). Besides being a p38-inhibitor, SB203580 is described as being an RIP2-inhibitor [28]. These data indicate that the effect of M-TriDAP treatment is mediated through p38 and/or RIP2-dependent pathways, which is in agreement with previous results describing RIP2 as a molecule of central importance to both Nod1 and Nod2 signalling [29]. In contrast, no significant inhibition was observed with inhibitors of JNK, MAPK and PI3K pathways, suggesting that neither of these pathways are utilized in these cells upon M-TriDAP stimulation.

Furthermore, to assess whether the stimulation mediated by M-TriDAP caused a general release of other proinflammatory cytokines and chemokines, we also measured secreted levels of MIP-1 $\alpha$, MIP-1 $\beta$, TNF, IL-1 $\beta$, GM-CSF and MCP-1 in the supernatants after $24 \mathrm{~h}$ of treatment with the Nod1 agonist M-TriDAP. In line with our observations for IL-8, the same pattern of release was obtained for the chemokines MIP- $1 \alpha$, MIP- $1 \beta$ and TNF (fig. $4 \mathrm{a}-\mathrm{c}$ ). No pronounced effect was observed on the release of IL-1 $\beta$, GM-CSF or MCP-1 (fig. 4d-f). Taken together, our results suggest that treatment of human CBMCs with M-TriDAP leads to secretion of several chemokines involved in the recruitment of inflammatory cells.

Additionally, we also investigated whether treatment of CBMCs with M-TriDAP stimulated release of human $\beta$-defensin 2 (HBD-2), an antimicrobial peptide. However, no release of HBD-2 could be detected when cells were treated with M-TriDAP alone, nor when combined with LPS or zymosan (data not shown). 


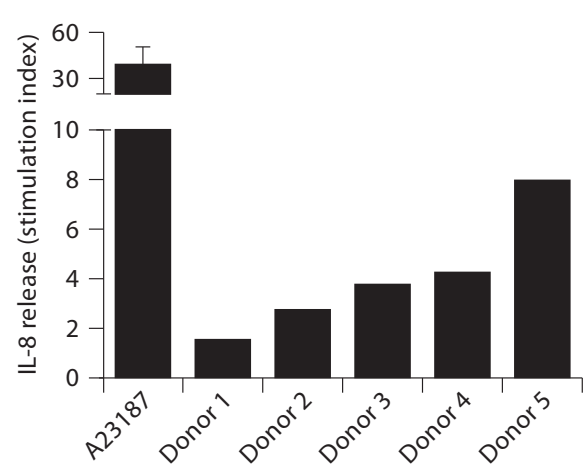

a

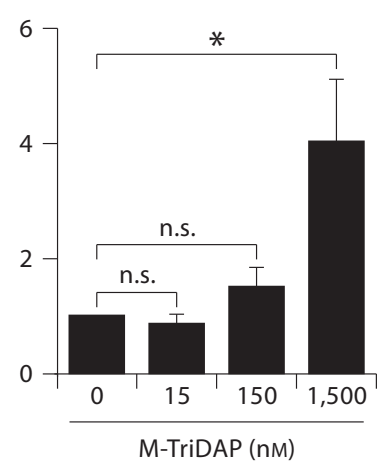

b

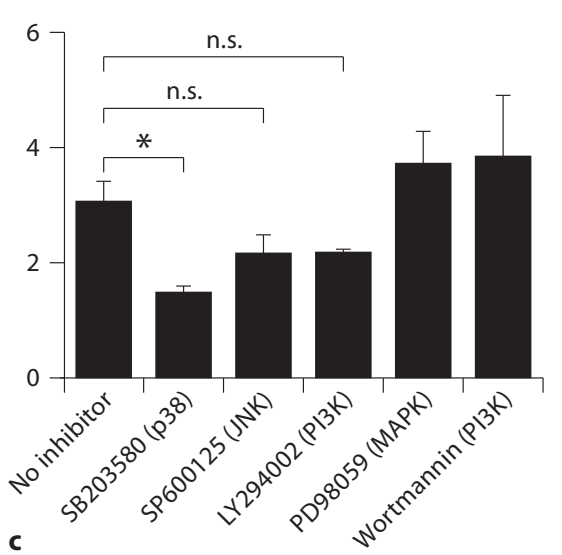

Fig. 3. M-TriDAP induces IL- 8 secretion in CBMCs through a p38-dependent mechanism. CBMCs were treated with M-TriDAP and supernatants were collected $24 \mathrm{~h}$ after treatment and analyzed for IL-8 presence using ELISA. a Donor variation in responses to treatment with 1,500 nM M-TriDAP. b Compiled data on IL-8 secretion by CBMCs treated with M-TriDAP. c CBMCs were pre- treated with selective inhibitors of cell signalling for $30 \mathrm{~min}$ prior to treatment with 1,500 nM M-TriDAP, after which IL- 8 secretion was determined as described above. Values are shown as stimulation index (treated/untreated). The values shown are means \pm SEM ( $\mathrm{n}=4-5$ healthy blood donors). ${ }^{*} \mathrm{p}<0.05$ in comparison to cells treated with medium alone. n.s. $=$ Not significant.
Fig. 4. M-TriDAP induces secretion of proinflammatory cytokines and chemokines in CBMCs. CBMCs were treated with 1,500 nM M-TriDAP for $24 \mathrm{~h}$, and secretion of MIP-1 $\alpha$ (a), MIP-1 $\beta$ (b), TNF (c), IL-1 $\beta$ (d), MCP-1 (e) and GM-CSF (f) was determined by cytometric bead array or LUMINEX. The values shown are means \pm SEM ( $\mathrm{n}=6-11$ healthy blood donors). ${ }^{*} \mathrm{p}<0.05$ in comparison to cells treated with medium alone. n.s. $=$ Not significant.

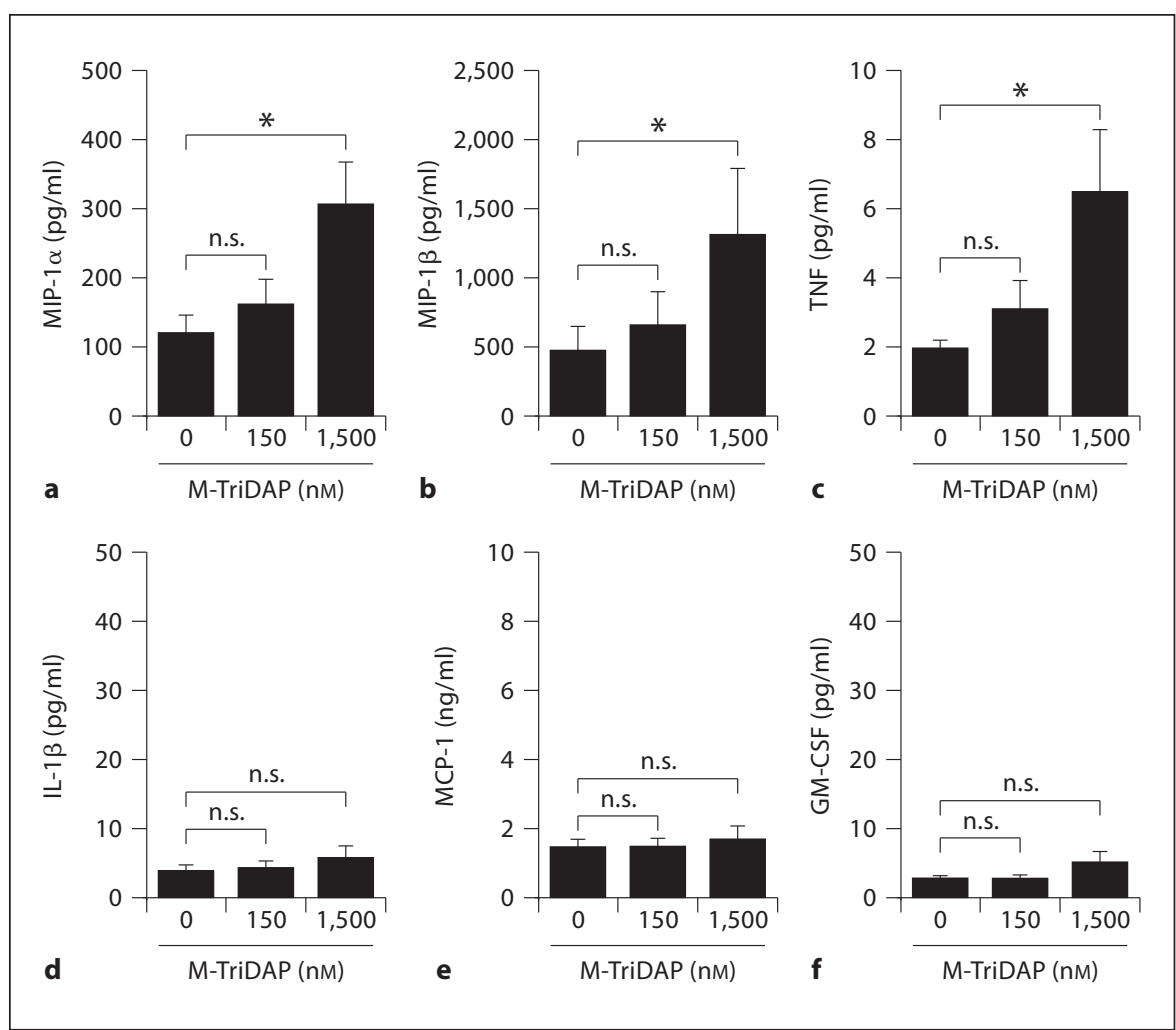


Fig. 5. M-TriDAP-induced IL-8 secretion in CBMCs is augmented if M-TriDAP is combined with TLR4 agonist LPS. CBMCs were treated with 1,500 nM M-TriDAP either alone, or combined with $0.1 \mu \mathrm{g} / \mathrm{ml}$ LPS (a) or $0.001 \mu \mathrm{g} / \mathrm{ml}$ zymosan (b), and IL- 8 secretion was determined by ELISA $24 \mathrm{~h}$ after treatment. Values are shown as stimulation index (treated/untreated). The values shown are means \pm SEM $(n=7-8$ healthy blood donors). ${ }^{*} \mathrm{p}<0.05,{ }^{* *} \mathrm{p}<$ 0.01 in comparison to cells treated with medium alone. n.s. $=$ Not significant.

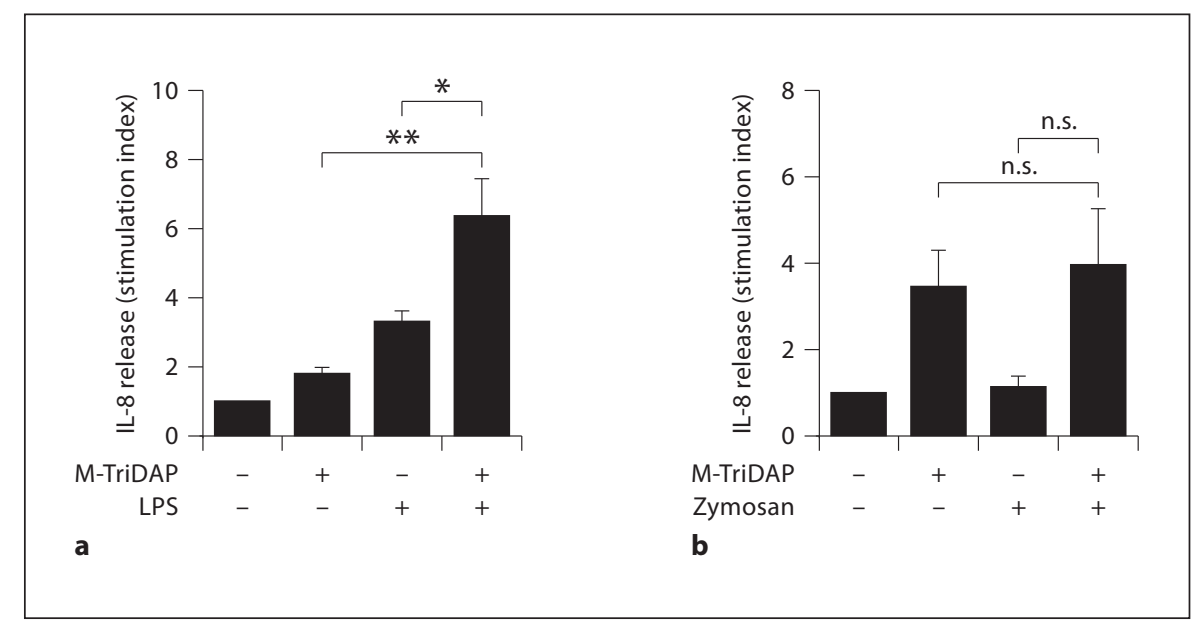

Human CBMCs Activated with M-TriDAP in Combination with LPS Secrete Enhanced Levels of $I L-8$

Several different endogenous and exogenous danger signals have been described to have an adjuvant function when combined with other stimuli [30]. To further investigate whether this is also the case for Nod-mediated stimulation of mast cells, we treated CBMCs simultaneously with different concentrations of M-TriDAP in combination with suboptimal concentrations of the TLR4 ligand LPS and the TLR2 ligand zymosan. Interestingly, as depicted in figure $5 \mathrm{a}$, we observed a synergistic effect of the co-stimulation with M-TriDAP in combination with LPS on IL-8 release. However, this effect was not seen when M-TriDAP was combined with zymosan (fig. 5b).

\section{Discussion}

We here present results demonstrating that primary human CBMCs from healthy blood donors express Nod1, but not Nod2, intracellularly, and are activated by the Nod1 agonist M-TriDAP alone and in combination with LPS to produce the pro-inflammatory cytokines and chemokines IL-8, MIP-1 $\alpha$, MIP- $1 \beta$ and TNF. When activating CBMCs with M-TriDAP, there was no significant induction of either degranulation (histamine release) or secretion of cysteinyl leukotrienes. These findings demonstrate that M-TriDAP stimulates mast cells through Nod1 to selectively produce and release cytokines, whereas degranulation of mast cells is not affected. Furthermore, our results indicate that the effect of Nod1 activates pathways involving p38 and/or RIP2.

Activation of Human Mast Cells by the

Nod1 Agonist M-TriDAP
When the immune system is exposed to pathogens, the pathogens are encountered as a mixture of potential activators rather than single purified agonists. Therefore, activating cells with combinations of Nod1 and TLR agonists most likely represent a more 'natural' pathogen stimulatory environment. Here, we observe that mast cells treated with M-TriDAP alone respond with low levels of released mediators compared to when they are treated with a combination of M-TriDAP and the TLR4 agonist LPS, where an augmented response is achieved. Surprisingly, combining M-TriDAP with the TLR2/dectin-1 ligand zymosan induces activation to a lesser degree than M-TriDAP in combination with LPS. One possible explanation could be that LPS and PGN, of which MTriDAP is a fragment, are also more likely to stimulate together than zymosan and PGN are.

Nod2 has been reported to be expressed in mast cell line HMC1.1 [31] and also in primary human mast cells [27]. In the latter study by Okumura et al. [27], Nod2 expression was found to be low in human mast cells, but was upregulated in IFN- $\gamma$ treated cells. In contrast to these studies, we could neither detect Nod 2 expression nor upregulate Nod 2 expression in CBMCs (fig. 1 and data not shown). It has previously been reported that treating CBMCs with MDP does not generate any detectable mast cell responses [32]. In agreement with this study, we observed neither histamine nor IL-8 release in CBMCs treated with MDP (data not shown). Previous findings reporting an increased number of $\mathrm{Nod} 2^{+}$mast cells in Crohn's disease patients [27] together with data from Haidl et al. [32], as well as our own data showing that CBMCs from healthy blood donors do not express Nod2, thus might suggest that Nod2-expressing mast

J Innate Immun 2011;3:142-149 
cells have a role in chronic diseases, but not in healthy individuals.

Our data from co-stimulations are consistent with other studies on monocytes, dendritic and epithelial cells showing a synergistic effect of Nod1 and TLR ligands on production of cytokines regulating the inflammatory response $[18,21,33,34]$. These findings together form a picture of NLRs having important functions in sensing invading pathogens or other danger signals together with the TLRs. Synergistic, or additive, effects induced by a combination of different agonists indicate the use of separate signalling pathways. NLRs activate $\mathrm{NF \kappa B}$ and JNK through the serine/threonine kinase Rip2 (receptor interacting protein 2), whereas the majority of the TLRs activate NFKB and MAPK by binding of the adaptor MyD88 $[29,35]$. Besides cooperation regarding signalling pathways, the receptors can also cross-talk in other ways. Nod1 has traditionally been described as an intracellular receptor, whereas most TLRs are sensing extracellular stimuli, and therefore, NLRs and TLRs may have different functions in clearance of bacteria [33]. TLR2 has recently been identified as a receptor for uptake of peptidoglycan, and once the absorption and transport of PGN through epithelial layers has taken place the peptidoglycan can be recognized by other cells through Nod1 [36]. However, members of the NLR family are also recruited to and localized at the plasma membrane when the cell encounters bacteria, suggesting that activation of Nod1 occurs at the site of initial bacterial contact [37].

Activation of mast cells through mainly TLR2, but also Nod1, turned out to be crucial for the outcome of Staphylococcus aureus peptidoglycan-induced enteritis (diarrhea), as shown in a recent study [36]. Mast cells also are essential for activation of lymph nodes when peptidoglycan is subjected intradermally. Without mast cells present, the Langerhans' cells in the skin will not migrate to the draining lymph node [38]. However, this effect is independent of TLR2, TLR4 and MyD88, suggesting a possible role for Nod1 in this activation. Furthermore, another connection between mast cells and PGN/Nod1 could involve NOD1 polymorphisms, which show a strong association to the presence of atopic eczema, asthma and elevated IgE levels [39-41].

This is one of the first studies specifically targeting Nod1 activation of primary human mast cells in vitro. Earlier studies report PGN stimulation of cultured human mast cells resulted in the release of pro-inflammatory cytokines and chemokines as well as histamine and leukotrienes [42-44], but the release of mediators is only partially inhibited by blocking with anti-TLR2 antibodies, suggesting that other receptors besides TLR2 are involved [44]. Our findings present compelling evidence that the intracellular Nod1 receptor is implicated in the activation of mast cells; a new way of activation which brings further pieces to the picture of mast cells as important players in the innate immune defence against pathogens.

\section{Acknowledgements}

We would like to thank Agnetha Beinhoff for expert help with the mast cell cultures, and Drs. Mireille Hervé and Dominique Mengin-Lecreulx (Université Paris-Sud, France) for kindly providing us with the M-TriDAP used in this study. The study was financially supported by funding to G.N. and C.L.A. from the Swedish Research Council - Medicine; Consul Th C Bergh's Foundation; Ollie and Elof Ericsson's Foundation; King Gustav V's 80-Years' Foundation; Ellen, Walter and Lennart Hesselman's Foundation; Prof. Nanna Schwartz' Foundation; Åke Wiberg's Foundation; Magnus Bergvall's Foundation and the Karolinska Institutet. S.M. was awarded an HQP exchange award, supported by the International Partnership Initiative between AllerGen NCE Inc. and the Centre for Allergy Research at the Karolinska Institutet.

\section{Disclosure Statement}

The authors have no conflicting financial interests.

\section{References}

1 Galli SJ, Nakae S, Tsai M: Mast cells in the development of adaptive immune responses. Nature Immunol 2005;6:135-142.

2 Marshall JS: Mast-cell responses to pathogens. Nat Rev Immunol 2004;4:787-799.

3 Kinet JP: The essential role of mast cells in orchestrating inflammation. Immunol Rev 2007;217:5-7.
4 Nathan C: Points of control in inflammation. Nature 2002;420:846-852.

5 Leslie M: Mast cells show their might. Science 2007;317:614-616.

6 Echtenacher B, Mannel DN, Hultner L: Critical protective role of mast cells in a model of acute septic peritonitis. Nature 1996;381:7577.
7 Malaviya R, Ikeda T, Ross E, Abraham SN Mast cell modulation of neutrophil influx and bacterial clearance at sites of infection through TNF-alpha. Nature 1996;381:7780.

8 Marshall JS, Jawdat DM: Mast cells in innate immunity. J Allergy Clin Immunol 2004;114: 21-27. 
$>9$ Supajatura V, Ushio H, Nakao A, Okumura $\mathrm{K}$, Ra C, Ogawa H: Protective roles of mast cells against enterobacterial infection are mediated by Toll-like receptor 4 . J Immunol 2001;167:2250-2256.

>10 Olynych TJ, Jakeman DL, Marshall JS: Fungal zymosan induces leukotriene production by human mast cells through a dectin-1-dependent mechanism. J Allergy Clin Immunol 2006;118:837-843.

-11 Malaviya R, Gao ZM, Thankavel K, van der Merwe PA, Abraham SN: The mast cell tumor necrosis factor alpha response to FIMHexpressing Escherichia coli is mediated by the glycosylphosphatidylinositol-anchored molecule cd48. Proc Natl Acad Sci USA 1999;96: 8110-8115.

-12 Marone G, Galli SJ, Kitamura Y: Probing the roles of mast cells and basophils in natural and acquired immunity, physiology and disease. Trends Immunol 2002;23:425-427.

$\checkmark 13$ Akira S, Uematsu S, Takeuchi O: Pathogen recognition and innate immunity. Cell 2006; 124:783-801.

$\checkmark 14$ Bianchi ME: Damps, pamps and alarmins: all we need to know about danger. J Leukoc Biol 2007;81:1-5.

-15 Takeuchi O, Akira S: Pattern recognition receptors and inflammation. Cell 2010;140: 805-820.

16 Fritz JH, Ferrero RL, Philpott DJ, Girardin SE: Nod-like proteins in immunity, inflammation and disease. Nat Immunol 2006;7: 1250-1257.

- 17 Chamaillard M, Girardin SE, Viala J, Philpott DJ: Nods, nalps and naip: Intracellular regulators of bacterial-induced inflammation. Cell Microbiol 2003;5:581-592.

-18 Ratner AJ, Aguilar JL, Shchepetov M, Lysenko ES, Weiser JN: Nod1 mediates cytoplasmic sensing of combinations of extracellular bacteria. Cell Microbiol 2007;9:1343-1351.

19 Viala J, Chaput C, Boneca IG, Cardona A, Girardin SE, Moran AP, Athman R, Memet S, Huerre MR, Coyle AJ, DiStefano PS, Sansonetti PJ, Labigne A, Bertin J, Philpott DJ, Ferrero RL: Nod1 responds to peptidoglycan delivered by the Helicobacter pylori CAG pathogenicity island. Nat Immunol 2004;5: 1166-1174.

20 Girardin SE, Travassos LH, Herve M, Blanot D, Boneca IG, Philpott DJ, Sansonetti PJ, Mengin-Lecreulx D: Peptidoglycan molecular requirements allowing detection by Nod 1 and Nod2. J Biol Chem 2003;278:4170241708.

-21 Fritz JH, Girardin SE, Fitting C, Werts C, Mengin-Lecreulx D, Caroff M, Cavaillon JM, Philpott DJ, Adib-Conquy M: Synergistic stimulation of human monocytes and dendritic cells by Toll-like receptor 4 and Nod1- and Nod2-activating agonists. Eur J Immunol 2005;35:2459-2470.

-22 van Heel DA, Ghosh S, Butler M, Hunt K, Foxwell BM, Mengin-Lecreulx D, Playford RJ: Synergistic enhancement of Toll-like receptor responses by Nod1 activation. Eur J Immunol 2005;35:2471-2476.
23 Nilsson G, Blom T, Harvima I, Kusche-Gullberg M, Nilsson K, Hellman L: Stem cell factor-dependent human cord blood derived mast cells express alpha- and beta-tryptase, heparin and chondroitin sulphate. Immunology 1996;88:308-314.

24 Saito H, Ebisawa M, Tachimoto H, Shichijo M, Fukagawa K, Matsumoto K, Iikura Y, Awaji T, Tsujimoto G, Yanagida M, Uzumaki $H$, Takahashi G, Tsuji K, Nakahata T: Selective growth of human mast cell induced by steel factor, IL-6, and prostaglandin E(2) from cord blood mononuclear cells. J Immunol 1996;157:343-350.

25 Harvima IT, Naukkarinen A, Harvima RJ, Horsmanheimo M: Enzyme- and immunohistochemical localization of mast cell tryptase in psoriatic skin. Arch Dermatol Res 1989;281:387-391.

26 Natsuka M, Uehara A, Yang S, Echigo S, Takada H: A polymer-type water-soluble peptidoglycan exhibited both Toll-like receptor 2- and Nod2-agonistic activities, resulting in synergistic activation of human monocytic cells. Innate Immun 2008;14: 298-308.

27 Okumura S, Yuki K, Kobayashi R, Okamura S, Ohmori K, Saito H, Ra C, Okayama Y: Hyperexpression of Nod2 in intestinal mast cells of Crohn's disease patients: preferential expression of inflammatory cell-recruiting molecules via Nod 2 in mast cells. Clin Immunol 2009;130:175-185.

28 Argast GM, Fausto N, Campbell JS: Inhibition of RIP2/RICK/CARDIAK activity by pyridinyl imidazole inhibitors of p38 mapk. Mol Cell Biochem 2005;268:129-140.

29 Park JH, Kim YG, McDonald C, Kanneganti TD, Hasegawa M, Body-Malapel M, Inohara N, Nunez G: Rick/rip2 mediates innate immune responses induced through Nod1 and Nod2 but not TLRs. J Immunol 2007;178: 2380-2386.

30 Rock KL, Hearn A, Chen CJ, Shi Y: Natural endogenous adjuvants. Springer Semin Immunopathol 2005;26:231-246.

> 31 Wu L, Feng BS, He SH, Zheng PY, Croitoru K, Yang PC: Bacterial peptidoglycan breaks down intestinal tolerance via mast cell activation: the role of TLR2 and Nod2. Immunol Cell Biol 2007;85:538-545.

32 Haidl ID, McAlpine SM, Marshall JS: Enhancement of mast cell IL- 6 production by combined toll-like and nucleotide-binding oligomerization domain-like receptor activation. Int Arch Allergy Immunol 2010;154: 227-235.

33 Masumoto J, Yang K, Varambally S, Hasegawa M, Tomlins SA, Qiu S, Fujimoto Y, Kawasaki A, Foster SJ, Horie Y, Mak TW, Nunez G, Chinnaiyan AM, Fukase K, Inohara N: Nod1 acts as an intracellular receptor to stimulate chemokine production and neutrophil recruitment in vivo. J Exp Med 2006; 203:203-213.
4 Uehara A, Yang S, Fujimoto Y, Fukase K, Kusumoto S, Shibata K, Sugawara S, Takada H: Muramyldipeptide and diaminopimelic acid-containing desmuramylpeptides in combination with chemically synthesized tolllike receptor agonists synergistically induced production of interleukin-8 in a Nod2- and Nod1-dependent manner, respectively, in human monocytic cells in culture. Cell Microbiol 2005;7:53-61.

35 Kufer TA, Sansonetti PJ: Sensing of bacteria: Nod a lonely job. Curr Opin Microbiol 2007; 10:62-69.

>36 Feng BS, He SH, Zheng PY, Wu L, Yang PC: Mast cells play a crucial role in Staphylococcus aureus peptidoglycan-induced diarrhea. Am J Pathol 2007;171:537-547.

37 Kufer TA, Kremmer E, Adam AC, Philpott DJ, Sansonetti PJ: The pattern-recognition molecule Nod1 is localized at the plasma membrane at sites of bacterial interaction. Cell Microbiol 2008;10:477-486.

38 Jawdat DM, Rowden G, Marshall JS: Mast cells have a pivotal role in TNF-independent lymph node hypertrophy and the mobilization of langerhans cells in response to bacterial peptidoglycan. J Immunol 2006;177: 1755-1762.

39 Eder W, Klimecki W, Yu L, von Mutius E, Riedler J, Braun-Fahrlander C, Nowak D, Holst O, Martinez FD, Team A: Association between exposure to farming, allergies and genetic variation in Card4/Nod1. Allergy 2006;61:1117-1124.

40 Hysi P, Kabesch M, Moffatt MF, Schedel M, Carr D, Zhang Y, Boardman B, von Mutius E, Weiland SK, Leupold W, Fritzsch C, Klopp N, Musk AW, James A, Nunez G, Inohara N, Cookson WO: Nod1 variation, immunoglobulin E and asthma. Hum Mol Genet 2005;14:935-941.

41 Weidinger S, Klopp N, Rummler L, Wagenpfeil S, Novak N, Baurecht HJ, Groer W, Darsow U, Heinrich J, Gauger A, Schafer T, Jakob T, Behrendt H, Wichmann HE, Ring J, Illig $\mathrm{T}$ : Association of Nod 1 polymorphisms with atopic eczema and related phenotypes. J Allergy Clin Immunol 2005;116:177-184.

42 Marshall JS, McCurdy JD, Olynych T: Tolllike receptor-mediated activation of mast cells: implications for allergic disease? Int Arch Allergy Immunol 2003;132:87-97.

43 McCurdy JD, Olynych TJ, Maher LH, Marshall JS: Cutting edge: distinct Toll-like receptor 2 activators selectively induce different classes of mediator production from human mast cells. J Immunol 2003;170:1625-1629.

44 Varadaradjalou S, Feger F, Thieblemont N, Ben Hamouda N, Pleau JM, Dy M, Arock M: Toll-like receptor 2 (TLR2) and TLR4 differentially activate human mast cells. Eur J Immunol 2003;33:899-906. 